Bartłomiej Matejko1, 2, Andrzej Gawrecki³ ${ }^{3}$ Marta Wróbel ${ }^{4}$, Jerzy Hohendorff², Teresa Benbenek-Klupa ${ }^{5}$, Maciej T. Malecki ${ }^{1}{ }^{2}$, Dorota Zozulińska-Ziółkiewicz ${ }^{3}$, Tomasz Klupa1, 2

${ }^{1}$ Department of Metabolic Diseases, Jagiellonian University Medical College, Krakow 2University Hospital, Krakow

${ }^{3}$ Department of Internal Medicine and Diabetology, Poznan University of Medical Sciences

${ }^{4}$ Clinical Department of Internal Diseases and Diabetology, Silesian Center for Heart Diseases, Zabrze

${ }^{5}$ DiabWay, Krakow

\title{
The association between the level of baseline daily physical activity and selected clinical and biochemical parameters during mountain trekking in patients with type 1 diabetes
}

\section{ABSTRACT}

Introduction. There is a general agreement that regular physical activity should be recommended for patients with type 1 diabetes mellitus (T1DM), as it positively affects blood pressure and lipid levels and diminishes the risk of T1DM complications. Aim of this study was to search for a correlation between lactate level, degree of fatigue, and patient-reported physical activity in T1DM patients while trekking up to $\mathbf{3 0 0 0}$ meters above sea level (masl).

Material and methods. Study group consisted of 19 participants ( 2 women) in mean age of 31 years with T1DM who summited 3000 masl in Alps. Clinical information was taken from patient questionnaire, personal insulin pumps and blood analysis (glucose, lactate level). Additionally patient self-assessment of physical activity and fatigue (Borg scale) was used.

Results. Declared physical activity in the last six months correlated with the initial, second, and final ratings of fatigue according to the Borg Scale during

Address for correspondence:

dr hab. n. med. Tomasz Klupa

Klinika Chorób Metabolicznych

Uniwersytet Jagielloński

ul. Kopernika 15, 31-501 Kraków

e-mail: tomasz_klupa@yahoo.com

Clinical Diabetology 2017, 6, 3, 77-80

DOI: $10.5603 /$ DK.2017.0013

Received: 10.05.2017

Accepted: 28.07.2017 the expedition day, $p=0.02, r=-0.65 ; p=0.02, r=$ $-0.54 ; p=0.01, r=-0.61$, respectively. Blood lactate levels tended to increase with duration of exercise and altitude. Also, the average level of lactate on the expedition correlated with the average level of fatigue ( $p=0.02, r=0.57$ ).

Conclusion. Before undertaking day-long mountain trekking, T1DM patients with a sedentary lifestyle should improve their fitness. The measurement of lactate levels can be a useful tool to predict fatigue as measured with the Borg Scale. (Clin Diabetol 2017; 6, 3: 77-80)

Key words: insulin pump, lactate level, physical fitness, diabetes type 1

\section{Introduction}

There is a general agreement that regular physical activity should be recommended for patients with type 1 diabetes mellitus (T1DM), as it positively affects blood pressure and lipid levels and diminishes the risk of T1DM complications such as cardiovascular disease [1]. Additionally, regular physical activity improves insulin sensitivity, which leads to a decrease in daily insulin requirements, and helps to control body weight [2]. It also promotes longevity in individuals with T1DM [3].

It is crucial to recommend a form of exercise for T1DM patients that is not only metabolically benefi- 
Table 1. Patient characteristics while summiting 3019 masl

\begin{tabular}{lccc}
\hline Variable & Mean & Median & Range \\
\hline Daily insulin dose [IU] & 39 & 36 & $20-84$ \\
Insulin dose per kg of body mass [IU/kg] & 0.52 & 0.52 & $0.26-0.84$ \\
Percentage of basal insulin (\%)* & 37 & 38 & $27-50$ \\
Mean glycemia [mg/dL] & 125 & 122 & $82-208$ \\
Number of carbohydrate exchangers [N] & 20 & 19 & $10-51$ \\
Lactate level at start [mmol/L] & 3.5 & 3.0 & $0.7-10.2$ \\
Lactate level at 2500 masl [mmol/L] & 3.4 & 2.8 & $0.9-7.8$ \\
Lactate level at 3019 masl [mmol/L] & 7.8 & 6.8 & $0.8-22$ \\
Lactate level at end point [mmol/L] & 6.6 & 5.0 & $0.9-22$ \\
Mean lactate level from 4 established time points [mmol/L] & 5.3 & 4.2 & $1.8-10.8$ \\
Number of hypoglycemia episodes [N] & 2 & 1 & $0-7$ \\
Borg Scale rating at start & 2.3 & 2.0 & $1-5$ \\
Borg Scale rating at 2500 masl & 3.3 & 3.0 & $1-6$ \\
Borg Scale rating at 3019 masl & 4.2 & 4.5 & $1-8$ \\
Borg Scale rating at end point & 4.0 & 4.0 & $1-8$ \\
Mean Borg Scale rating from 4 established time points & 3.6 & 3.3 & $1-6.2$ \\
\hline
\end{tabular}

*Data taken from insulin pumps (or from patient diaries for MDI patients) during the last 30 days

cial but also relaxing and enjoyable, simply enabling patients to have fun. Mountain trekking can certainly serve as an effective way to engage in physical activity for individuals with T1DM. It may help T1DM patients to increase skills in diabetes self-management, provides an opportunity for them to socialize with other patients, and may be entertaining and satisfying for participants. However, day-long mountain trekking may be a challenge for T1DM patients, as it requires many hours of intense aerobic and interval exercise. Crucial factors for optimal insulin management during such types of exercise have not yet been established [4, 5]. It is known that blood lactate level is useful marker of physical fitness, muscle fatigue, and adaptation to endurance training, such as mountain trekking $[6,7]$.

The aim of our study was to search for a correlation between lactate level, degree of fatigue (using the 0-10 Borg Scale), and patient-reported physical activity, as well as the parameters obtained from a patient questionnaire and data collected from insulin pumps in T1DM patients while trekking up to 3000 meters above sea level (masl).

\section{Material and methods}

The mountain trekking activity, with the aim to reach 3000 masl, took place in the Alps (Similaun Hütte, 3019 masl, the Otzal Alps) and consisted of 19 participants ( 2 women) with T1DM and the following characteristics: mean age of 31 years (range 23-43 years); mean BMI of $23.5 \mathrm{~kg} / \mathrm{m}^{2}$ (range $19.8-30.5 \mathrm{~kg} / \mathrm{m}^{2}$ ); mean $\mathrm{HbA}_{1 \mathrm{c}}$ level of $6.5 \%-48 \mathrm{mmol} / \mathrm{mol}$ (range
$5.4-7.8 \%$ - range $36-62 \mathrm{mmol} / \mathrm{mol}) ;$ mean diabetes duration of 12 years (range 1-31 years); and without chronic complications (Tab. 1). Most patients were treated with personal insulin pumps [2 patients received multiple daily injections (MDI) of insulin]. All participants in the trekking expedition completed a questionnaire with data regarding blood glucose measurements, total daily insulin dose, percentage of basal insulin, and number of carbohydrate exchangers during the trekking expedition and during the last 30 days. Participants were also asked to measure and record their blood lactate concentration at four time points: (1) at the beginning of the expedition, (2) at 2500 masl, (3) at 3019 masl, and (4) after returning to the bus (the end point).

Perceived exertion was measured using the Borg Rating of Perceived Exertion Scale (RPE scale), which rates perceived exertion from 0 (no physical effort) to 10 (maximal physical effort). Participants were asked to record Borg Scale ratings at the same 4 time points as listed above. Blood lactate level was used to assess the degree of severity of anaerobic glycolysis (Lactate Scout, EKF-Diagnostics). Additionally patient self-assessment of physical activity before trekking day was used [answer to question: "How active were you during last six months?" rated on a scale of 1 (inactive) to 8 (highly active)].

Normality was assessed with Shappiro-Wilk test and based on it we chose nonparametric Spearman correlation to evaluate the relationship between variables (correlation coefficient $r$ and $p$-value were shown). Correlation was declared significant at $p<0.05$. Sta- 
Table 2. Main results of correlation analysis

\begin{tabular}{|c|c|c|}
\hline Correlated variables & $\mathbf{r}$ & $\mathbf{p}$ \\
\hline Self-reported physical activity — daily insulin dose [IU]* & 0.00 & 0.98 \\
\hline Self-reported physical activity — insulin dose per $\mathrm{kg}$ of body mass [IU/kg]* & -0.03 & 0.91 \\
\hline Self-reported physical activity — age & 0.31 & 0.18 \\
\hline Self-reported physical activity $-\mathrm{HbA}_{1 \mathrm{c}}$ & -0.07 & 0.78 \\
\hline Self-reported physical activity — diabetes duration & -0.22 & 0.36 \\
\hline Self-reported physical activity — Borg Scale rating at start & -0.65 & 0.02 \\
\hline Self-reported physical activity - Borg Scale rating at 2500 masl & -0.54 & 0.02 \\
\hline Self-reported physical activity — Borg Scale rating at 3019 masl & -0.15 & 0.55 \\
\hline Self-reported physical activity — Borg Scale rating at end point & -0.61 & 0.01 \\
\hline Lactate level at start $[\mathrm{mmol} / \mathrm{L}]$ - Borg Scale rating at start & 0.48 & 0.13 \\
\hline Lactate level at $2500 \mathrm{masl}[\mathrm{mmol} / \mathrm{L}]$ — Borg Scale rating at 2500 & 0.52 & 0.05 \\
\hline Lactate level at end point $[\mathrm{mmol} / \mathrm{L}]$ — Borg Scale rating at 3019 masl & 0.60 & 0.02 \\
\hline Mean lactate level [mmol/L] — Mean Borg Scale & 0.57 & 0.02 \\
\hline
\end{tabular}

tistical analyses were performed with the R statistical programming language (ver. 3.2.3).

\section{Results}

Declared physical activity in the last six months correlated with the initial, second, and final ratings of fatigue according to the Borg Scale during the expedition day: $p=0.02, r=-0.65 ; p=0.02, r=-0.54 ; p=0.01$, $r=-0.61$, respectively (at third point at 3019 masl this correlation was not statistically significant, Tab. 2). There was no correlation between the Borg Scale ratings and mean glycemia on the day of the expedition.

Blood lactate levels tended to increase with duration of exercise and altitude (from $3.5 \mathrm{mmol} / \mathrm{L}$ at 1950 masl to $7.8 \mathrm{mmol} / \mathrm{L}$ at 3019 masl). Lactate levels at the beginning of the expedition (Tab. 1) did not correlate with Borg Scale ratings ( $p=0.13, r=0.48$ ), however, as the trekked altitude increased, this correlation achieved statistical significance (at 2500 masl: $p=0.056, r=0.52$; at 3019 masl: $p=0.02, r=0.60)$. Also, the average level of lactate on the expedition $(5.3 \mathrm{mmol} / \mathrm{L})$ correlated with the average level of fatigue (3.6 on the Borg Scale, $p=0.02, r=0.57$ ). During the day of the expedition, there was no correlation between mean lactate level and mean glucose level $(p=0.73)$, increase or decrease in insulin requirement $(p=0.49)$, or number of hypo- ( $<70 \mathrm{mg} / \mathrm{dL}$ ) or hyperglycemic episodes ( $>250 \mathrm{mg} / \mathrm{dL})(\mathrm{p}=0.41$ and $\mathrm{p}=0.66$, respectively). There was, however, a significant correlation between mean lactate level and insulin requirement during the last 30 days $(p=0.005, r=0.64)$.

\section{Discussion}

It is not surprising that the declared baseline level of physical activity correlated with fatigue during trek- king as measured with the Borg Scale, especially at higher altitudes. Higher fatigue levels make trekking less pleasant. Severe levels of fatigue may result in problems with glucose management (however, this result was not observed during our expedition). Higher fatigue levels may also lead to impaired hypoglycemia awareness [8]. Thus, it should be recommended for sedentary or deconditioned individuals with T1DM to go through an initial training phase to improve their physical fitness level before day-long mountain trekking.

As far as lactate is concerned, our findings are consistent with previous research in which lactate levels were significantly higher in T1DM patients who performed exercise with greater intensity [9]. It was shown that plasma lactate concentration is also associated with the degree of fatigue [10].

In our study, we found that mean plasma lactate correlated positively with daily insulin requirement during the last 30 days. This observation may simply reflect the fact that T1DM individuals that are less fit at baseline and are prone to produce more lactate during mountain trekking require more insulin before expedition due to a sedentary lifestyle. This is in contrast to more fit individuals, who were able to decrease their daily insulin demand before trekking due to higher levels of physical activity. We cannot, however, exclude the direct impact of lactate on insulin requirements $[11,12]$.

We are not sure, however, to what degree lactate levels were increased due to a longer duration of exercise or to higher altitude. It is also known that the Borg Scale is a useful tool to predict lactate levels in healthy people ( $p<0.001, r=0.83$ ) and also in people with metabolic syndrome who perform exercise with differ- 
ent intensities $[13,14]$. This study, for the first time, shows that during mountain trekking, fatigue, as measured with the Borg Scale, correlates with lactate levels in individuals with T1DM. This means that increased lactate levels may predict physical decondition during prolonged exercise in patients with T1DM, which could not only be unpleasant, but also dangerous during mountain trekking at higher altitudes. The discussion concerning the measurement of lactate levels during trekking is not just a theoretical exercise - nowadays, light and small devices for lactate level determination are available (as utilized by us) and can be easily used in mountain conditions. We do not recommend routine lactate level measurements during mountain trekking, but it can be a useful option for especially challenging expeditions.

\section{Conclusions}

In adult T1DM patients the lower baseline physical activity the higher fatigue (which reflect blood lactate level) during exercise is observed. Before undertaking day-long mountain trekking, T1DM patients with a sedentary lifestyle should improve their fitness. The measurement of lactate levels can be a useful tool to predict fatigue as measured with the Borg Scale.

\section{Statement of Human and Animal Rights}

All procedures followed were in accordance with the ethical standards of the responsible committee on human experimentation (institutional and national) and the Helsinki Declaration of 1975, as revised in 2008.

\section{Statement of Informed Consent}

Informed consent was obtained from all patients included in the study.

\section{REFERENCES}

1. Maahs DM, Nadeau K, Snell-Bergeon JK, et al. Association of insulin sensitivity to lipids across the lifespan in people with Type 1 diabetes. Diabet Med. 2011; 28(2): 148-155, doi: 10.1111/j.14645491.2010.03143 $x$, indexed in Pubmed: 21219421.
2. Ramalho AC, de Lourdes Lima M, Nunes F, et al. The effect of resistance versus aerobic training on metabolic control in patients with type-1 diabetes mellitus. Diabetes Res Clin Pract. 2006; 72(3): 271-276, doi: 10.1016/j.diabres.2005.11.011, indexed in Pubmed: 16406128.

3. Stessman J, Jacobs JM. Diabetes Mellitus, Physical Activity, and Longevity Between the Ages of 70 and 90. J Am Geriatr Soc. 2014 [Epub ahead of print], doi: 10.1111/jgs.12930, indexed in Pubmed: 25040133.

4. Johnson NJ, Luks AM. High-Altitude Medicine. Med Clin North Am. 2016; 100(2): 357-369, doi: 10.1016/j.mcna.2015.09.002, indexed in Pubmed: 26900119.

5. de Mol P, de Vries ST, de Koning EJP, et al. Physical activity at altitude: challenges for people with diabetes: a review. Diabetes Care. 2014; 37(8): 2404-2413, doi: 10.2337/dc13-2302, indexed in Pubmed: 25061142.

6. Owles WH. Alterations in the lactic acid content of the blood as a result of light exercise, and associated changes in the co(2)-combining power of the blood and in the alveolar $\mathrm{co}(2)$ pressure. J Physiol. 1930; 69(2): 214-237, doi: 10.1113/jphysiol.1930. sp002646, indexed in Pubmed: 16994099

7. Yoshida Y, Holloway GP, Ljubicic V, et al. Negligible direct lactate oxidation in subsarcolemmal and intermyofibrillar mitochondria obtained from red and white rat skeletal muscle. J Physiol. 2007; 582(Pt 3): 1317-1335.

8. Basu R, Johnson ML, Kudva YC, et al. Exercise, hypoglycemia, and type 1 diabetes. Diabetes Technol Ther. 2014; 16(6): 331-337, doi: 10.1089/dia.2014.0097, indexed in Pubmed: 24811269.

9. Bally L, Zueger T, Pasi N, et al. Accuracy of continuous glucose monitoring during differing exercise conditions. Diabetes Res Clin Pract. 2016; 112: 1-5, doi: 10.1016/j.diabres.2015.11.012, indexed in Pubmed: 26739116.

10. Romijn JA, Coyle EF, Sidossis LS, et al. Substrate metabolism during different exercise intensities in endurance-trained women. J Appl Physiol (1985). 2000; 88(5): 1707-1714, indexed in Pubmed: 10797133.

11. Adeva-Andany $M$, López-Ojén $M$, Funcasta-Calderón $R$, et al. Comprehensive review on lactate metabolism in human health. Mitochondrion. 2014; 17: 76-100, doi: 10.1016/j.mito.2014.05.007, indexed in Pubmed: 24929216.

12. Emhoff CAW, Messonnier LA, Horning MA, et al. Gluconeogenesis and hepatic glycogenolysis during exercise at the lactate threshold. J Appl Physiol (1985). 2013; 114(3): 297-306, doi: 10.1152/ /japplphysiol.01202.2012, indexed in Pubmed: 23239870.

13. Irving BA, Rutkowski J, Brock DW, et al. Comparison of Borg- and OMNI-RPE as markers of the blood lactate response to exercise. Med Sci Sports Exerc. 2006; 38(7): 1348-1352, doi: 10.1249/01. mss.0000227322.61964.d2, indexed in Pubmed: 16826034.

14. Scherr J, Wolfarth B, Christle JW, et al. Associations between Borg's rating of perceived exertion and physiological measures of exercise intensity. Eur J Appl Physiol. 2013; 113(1): 147-155, doi: 10.1007/s00421-012-2421-x, indexed in Pubmed: 22615009 